\title{
Enhancing Labour Force Participation for People Living with HIV: A Multi-Perspective Summary of the Research Evidence
}

\author{
Catherine Worthington, Kelly O’Brien, Elisse Zack, Eileen Mckee, \\ and Brent Oliver
}

Version Post-Print/Accepted Manuscript

Citation Worthington C, O’Brien KK, Zack E, McKee E, Oliver B. Enhancing

(published version) Labour Force Participation for People Living with HIV: A Multi-

Perspective Summary of the Research Evidence. AIDS and Behavior. January 2012; 16(1):231-243.

Publisher's Statement The final publication is available at Springer via http://dx.doi.org/10.1007/s10461-011-9986-y.

How to cite TSpace items

Always cite the published version, so the author(s) will receive recognition through services that track citation counts, e.g. Scopus. If you need to cite the page number of the TSpace version (original manuscript or accepted manuscript) because you cannot access the published version, then cite the TSpace version in addition to the published version using the permanent URI (handle) found on the record page. 


\title{
Enhancing Labour Force Participation for People Living with HIV: A Multi-Perspective Summary of the Research Evidence
}

\author{
Catherine Worthington • Kelly O’Brien •Elisse Zack • Eileen Mckee • Brent Oliver
}

\begin{abstract}
AIDS Behav (2012) 16:231-243
DOI 10.1007/s10461-011-9986-y

Electronic supplementary material: The online version of this article contains supplementary material, which is available to authorized users.
\end{abstract}

\begin{abstract}
Labour force participation has been identified as a critical social and health issue facing people living with HIV/AIDS (PHAs). We conducted a scoping study (a form of literature synthesis that summarizes research findings, research activity, and identifies literature strengths and gaps) on labour force participation for PHAs, guided by a community advisory committee. We summarized information from 243 peer-reviewed articles and 42 reports from the grey literature, and synthesized the evidence into a preliminary conceptual framework with five components: (1) the meaning of work, (2) key factors (barriers and facilitators) influencing labour force participation, (3) factors affecting vulnerable populations, (4) strategies and supports for returning to or sustaining work, and (5) outcomes (benefits and risks) of labour force participation for individuals and employers. The framework supports the development of labour force initiatives requiring collaborative efforts in multiple domains (health, employment, community) by PHAs, rehabilitation professionals, employers, insurers, and policy makers.
\end{abstract}

Keywords: HIV _ Employment_ Scoping study _ Vocational rehabilitation 


\section{INTRODUCTION}

Labour force participation has been identified as a critical social issue facing people living with HIV/AIDS (PHAs) in North America and Northern and Central Europe.[1-3] Recent studies suggest that approximately half (42\%-62\%) of PHAs in industrialized countries are unemployed.[4-8] While the links between health and labour force participation are complex, it is clear that labour force participation is an important intermediate social driver and determinant of health.[9-13] Labour force participation provides a means to income, and may also increase psychological health and quality of life through daily life structure and social linkages.[4, 14-16] However, research into labour force participation for PHAs is in the early stages. [17]

The success of new medications has meant that HIV, though ultimately fatal, increasingly is experienced as an episodic disease, characterized by unpredictable cycles of wellness and illness.[18, 19] In order to escape the effects of poverty and often inadequate income support programs, an increasing number of PHAs are considering labour force entry, reentry, or are struggling to maintain paid employment while dealing with sequelae of HIV, including depression, physical limitations and fatigue.[3, 20] Distinct social features of HIV that create barriers to engaging in employment include discrimination in employment practices and stigmatization of PHAs, the lack of HIV-friendly workplace policies (e.g., job accommodation), as well as potential benefits loss (public and private insurance).[21] Vocational rehabilitation programs for PHAs are underfunded and in the early stages of development, exacerbating gaps in income supports for PHAs.[22]

In an effort to improve and develop vocational programs and policies for PHAs, several primarily US-based studies have attempted to conceptualize the key factors and processes related to HIV/AIDS and employment.[23] Several frameworks and models have been developed 
drawing primarily on psychological and vocational counselling perspectives and adapted based on research conducted with PHAs. [1, 23-25] Unfortunately, these efforts have been fragmented, often using dissimilar language to describe key concepts.[17] There are only a handful of HIVspecific employment programs in North America concentrated in large urban centres, and much work is required to address inconsistent benefit and income support structures that influence the employment options of many PHAs.[1] The most recent literature reviews and syntheses conducted by Braveman (2006) and Werth (2008) identified very few articles related to the needs and barriers influencing return to work for PHAs and the vocational services designed to address them.[3, 26] Thus, very little research evidence exists to inform social policy and effective community programming that could support the employment-related needs of PHAs.[17] A better understanding of the current literature base related to labour force participation for PHAs is a key step to developing employment programs and policy that will improve care, treatment and support.

The purpose of this scoping study was to build upon the previous reviews of the literature (Braveman, 2006, Werth 2008) to summarize the extent, range and nature of the literature on labour force participation for PHAs in order to inform future strategies and interventions to promote the successful labour force participation for PHAs in Canada. Thus, in this scoping study we were interested in examining the literature (including peer reviewed and grey literature) on contextual factors, including personal, social, and structural barriers and facilitators for labour force participation and program interventions. Results of the scoping study include a preliminary conceptual framework that summarizes existing literature on labour force participation for PHAs. While the results are most relevant in North American contexts, they may also be of interest in other high income countries. 


\section{METHODS}

A scoping study is a form of literature synthesis used to map the key concepts underpinning a research area and the main sources and types of evidence available when an area is complex or has not been reviewed comprehensively before.[27] Scoping studies may be used to summarize and disseminate research findings, demonstrate the extent and range of research activity, and identify strengths and gaps in the existing literature.[28] We used the Arksey and O’Malley scoping review framework to guide our scoping study process.[28] Our scoping study was a partnership with the Canadian Working Group on HIV and Rehabilitation (CWGHR), and was guided by a community advisory committee of six people that included PHAs, employers, service providers, insurers, and policy makers. Research ethics approval for this study was obtained from the University of Calgary and the University of Toronto.

We reviewed published peer reviewed journal articles and the grey literature (reports, policy papers, etc.) to explore the topic of labour force participation for PHAs. For the purposes of this research, we defined labour force participation as working for pay or profit in the context of an employer-employee relationship or self employment (thus excluding “under-the-table” or volunteer types of work).[29] While we were interested primarily in work relevant to the Canadian context, we included sources from around the world if they were considered applicable. The scoping study was conducted in four main phases:

1. Identifying relevant literature: A list of key words and phrases related to HIV, AIDS, employment and vocational counseling and rehabilitation was developed in order to conduct a thorough search of the peer reviewed literature (a list of key words is available on request). We then searched five electronic databases including ABI, PsycINFO, MEDLINE, 
EMBASE, and CINAHL from 1980 to the end of February 2008. The search strategy identified 11,165 potentially relevant abstracts.

Grey literature documents were identified and gathered through members of the community advisory committee, reference lists, existing networks, and an extensive web search. For the web search, we utilized Google and searched the first 270 of approximately 210,000 search results. After this point, the number of relevant hits was less than 1 in 29, and so the search process was stopped.

2. Study selection: For the peer reviewed literature, two authors independently reviewed all abstracts and made recommendations for deferral, inclusion and exclusion. Peer reviewed articles included in the scoping review were restricted to those that addressed factors related to labour force participation, were published in English or French and were conducted primarily in developed countries. Articles primarily related to developing countries, occupational exposure, AIDS education, HIV transmission, the American Disabilities Act, and the insurance industry were excluded. Sixty-two articles were unavailable or published in a foreign language and were consequently excluded from the scoping study. Two hundred and forty-three (243) peer reviewed articles met the inclusion criteria.

The grey literature was reviewed by two members of the research team. Inclusion criteria for the grey literature were the same as for the peer reviewed literature. In all, 42 additional relevant documents were reviewed from the grey literature.

3. Charting the data: Data from the relevant peer reviewed articles and the grey literature were combined and extracted onto a standardized charting form by one research team member and three trained research assistants. Data extracted included author, year, aims of the study, population, methodology, outcomes, key findings, study / report limitations, and 
ratings of high, medium and low relevance of the document for the framework. Frequent consultation and two separate validity checks were conducted to ensure consistency and rigor. The team met throughout to ensure clarity and consensus surrounding the nature and extent of data extracted from the studies.

4. Collating, summarizing and reporting the results: One team member reviewed, summarized, and organized the extracted data according to key themes. These themes were then presented for discussion and consultation with the entire research team including the advisory committee members, who collaborated on finalizing the themes from the scoping study. These themes were identified and entered into a compendium table with links to specific references. Results were then synthesized into a preliminary conceptual framework of labour force participation for PHAs, including five key themes that incorporate the role of PHAs, employers, insurers and policy in labour force participation. A summary table of the literature rated as the most highly relevant to the framework (i.e., rated high relevance during the data charting) was created, consisting of 92 entries (Table 1).

\section{RESULTS}

Reported results represent evidence from both the peer reviewed and grey literature. Eighty-nine percent (253 articles) of the labour force participation literature we reviewed originated after combination antiretroviral therapy became standard (post-1996) when many PHAs began exploring the possibility of returning to the paid workforce. The literature reviewed included a wide range of research methodologies. Most articles (47\%) utilized a quantitative design (e.g., quasi-experimental designs), while 20\% utilized qualitative methods (e.g., grounded theory). Research that explicitly identified the use of participatory and mixed methods 
approaches made up $6 \%$ of the included studies. The remaining labour force participation literature (approximately 27\%) consisted of reviews, discussion papers and theoretical articles. The labour force participation literature was interdisciplinary in nature and included contributions from several fields, including counseling and vocational psychology, vocational rehabilitation, occupational therapy, physical therapy, social work, and the health sciences. The majority (69\%) of the labour force participation literature drew from samples of PHAs or documented their perspectives, behaviours and experiences. Thirteen percent of the articles focused on the policy and legislative environment governing labour force participation for PHAs; 9\% addressed the experiences and perspectives of employers, and 9\% addressed issues pertaining to vocational rehabilitation and associated service providers. Table I (available via electronic supplementary material) displays the 92 references rated as high relevance by the team; a full bibliography is available from the authors on request.

The preliminary conceptual framework represents a summary of the evidence on labour force participation for PHAs emanating from the labour force participation literature. The preliminary framework incorporates key themes from the scoping review of the published and grey literature. These themes were summarized into five broad components that reflect the literature base in the area to date: 1) the meaning of work, 2) key factors (barriers and facilitators) influencing labour force participation, 3) factors affecting vulnerable populations, 4) strategies and supports for returning to or sustaining work, and 5) outcomes (benefits and risks) of labour force participation for individuals and employers. The findings within each category are summarized in the following sections.

\section{The Meaning of Work}


Unemployment rates among PHAs in developed countries are considerably higher than those among the general population.[30-32] The labour force participation literature suggests that a significant number of PHAs are at risk of losing their jobs immediately following their diagnosis.[32] However, the literature demonstrates that a high percentage (up to 74\%) of PHAs would prefer to be engaged in the paid workforce.[33]

Several studies using a psychological or sociological perspective have described the underlying value and significance that PHAs attribute towards work and the ways it influences their decisions related to labour force participation. Principally, work plays a role in satisfying an individual's need for survival, social connection and self determination.[16, 34] The current evidence on employment for PHAs reinforces labour force participation as a complex and uncertain process characterized by multiple transitions between work and unemployment due to illness.[35] An individual's approach to labour force participation may vary based on a variety of complex factors including personal history, environmental influences and his/her experience with HIV. Accordingly, PHAs may be maintaining ongoing employment, considering return to work or entering the labour force for the first time. Their participation in paid employment may involve a diversity of forms including part time, full time and contract positions.[1, 35] They may also be considering a variety of alternative vocational activities or rehabilitation programs a range of techniques or interventions that can be applied to maintain, restore, or enhance aspects of health and quality of life.[36] In this case, volunteering, work trials and returning to school may also be important considerations for PHAs planning to enter the workplace.[1, 16, 37] The labour force participation literature identifies several factors that motivate PHAs to consider labour force participation. Essentially, work provides increased access to financial resources, affordable insurance coverage and quality health care.[1, 38-40] Additionally, many PHAs share 
the belief that involvement in the workforce will provide physical and emotional benefits including improved health, better stress management, increased self-esteem and greater independence.[39, 41] Several studies suggest that PHAs are sensitive to prevalent cultural values regarding work and often experience social pressure that encourages them to contribute to society through paid employment.[41, 42] Accordingly, the concept of work is frequently entwined with an individual's sense of personal and occupational identity. From this sociological perspective, transitions related to labour force participation may include the need to create or recreate a sense of identity in a worker role while leaving behind a "sick role” identity.[34, 43] Finally, improved health due to combination antiretroviral therapy (cART) has meant that many PHAs no longer qualify for disability benefits and have no choice but to work in order to support themselves and their families.[17]

\section{Key Factors Influencing Labour Force Participation (Barriers and Facilitators)}

A predominant focus of much of the literature addressing labour force participation for PHAs has been to identify barriers and facilitators that influence the employment experiences of PHAs. Maguire et al. (2008) conceptualized these processes as occurring within three main categories: the health, employment and community domains.[23]

\section{Health Domain}

Health Status, Episodic Nature of HIV and Disease Progression. As might be expected, the labour force participation literature suggests that a PHA's health status affects his/her likelihood of working, as well as the quality and variety of his/her employment options.[44] In this respect, health related factors may serve as both facilitators and barriers of employment for PHAs. A range of barriers related to health status have frequently been documented in the literature as negatively affecting the employment experiences of PHAs. Having been diagnosed with AIDS or 
living with an advanced stage of HIV disease is viewed as a key barrier to employment, as is the episodic nature of the illness and related uncertainty.[25, 39, 45, 46] Additionally, increased symptoms of HIV and related conditions such as fatigue, physical limitations, and cognitive and neuropsychological impairments, can serve as obstacles to employment.[47-50] While access to effective treatment is frequently considered a precondition to employment, issues related to medication still serve as significant barriers. Difficulties related to medication adherence and complicated scheduling regimens have traditionally inhibited employment for PHAs.[48] Moreover, debilitating side effects attributed to some cART regimens can prevent PHAs from effectively contributing to the workforce.[51] In addition, Hepatitis C co-infection and other concurrent conditions further compromise the health status of some PHAs and exist as additional barriers to employment.[32, 45]

Conversely, some studies indicate that a successful cART regimen and subsequent improved health are related to successful employment for PHAs.[51, 52] Being asymptomatic, having an undetectable viral load and being in the early stages of disease progression are health related factors that facilitate successful labour force participation.[51, 52] Early access to cART for PHAs who are already working can impede disease progression and assist in sustaining longer term employment.[52]

Emotional and Psychological Factors. Emotional and psychological factors are commonly cited as barriers to employment for some PHAs and often precipitate their leaving the workplace.[39, 53] Several studies have identified a range of emotional and psychological challenges associated with HIV infection that inhibit labour force participation. Foremost among these is depression commonly experienced by PHAs.[8, 48, 54] Several employment studies conducted with PHAs have also described their experiences of fear, anxiety, shame, and a low sense of self worth; 
emotional factors that may prevent successful employment.[8, 39] Vocational barriers related to HIV can also include post traumatic stress disorder, suicidal ideation and other serious psychiatric disabilities.[16, 35, 55] Adding to this stress for many PHAs are external social pressures that may for some reinforce a sick role identity and therefore discourage employment.[42]

On the other hand, there are corresponding personal strengths that act as employment facilitators. A number of studies have proposed that a strong sense of personal identity and a positive view of self in a worker role contribute to successful engagement in the work force.[23, 56, 57] Furthermore previous personal experiences with a similar, serious life challenge, strong personal motivation, and good interpersonal skills have been described as having a facilitative effect in employment situations.[23, 58]

\section{Employment Domain}

A second theme within the barriers and facilitators category is the employment domain. The labour force participation literature identifies several key factors within this domain. Income Protection, Insurance and Benefits. Evidence suggests that multiple issues related to income maintenance and insurance coverage are a critical concern for PHAs.[59] Regardless of employment status or type of insurance, PHAs and service providers frequently cite the complex rules surrounding health and disability benefits regimes as significant barriers to employment.[59] For those who are not currently participating in the workplace, the potential loss of public health benefits is frequently reported as a primary fear and subsequent disincentive for contemplating a return to work.[1, 35, 39, 48, 60, 61] For those who are covered through long term disability by a private sector insurer, return to work also represents an enhanced risk of losing their current disability benefits and drug coverage.[42] This is exacerbated by a lack of 
information regarding disability benefit contracts and the possibility of inadequate coverage by a new employer.[39] The literature documents similar fears among individuals who are receiving public benefits.[62, 63] In this case, returning to work raises the added possibility that low wages would not provide a level of income similar to that provided by social benefits.[64] For those already employed, the lack of portability of insurance coverage exists as a considerable barrier to vocational planning and career development.[1] [40] Consequently, several studies have advocated for flexible disability pension structures and increased access to benefits, income supplements and health insurance as facilitators of labour force participation for PHAs.[1, 48, 62, 65]

Stigma and Discrimination. A history of discrimination in the workplace, perceptions of prejudice, and the stigmatizing nature of HIV/AIDS combine to create complex barriers for PHAs in employment situations.[32, 39, 62] Work place discrimination is discussed in a wide range of studies examining labour force participation for PHAs.[32, 33, 61, 62, 66] Conyers has documented deep levels of discrimination targeted towards PHAs in the American work place and an increased level in comparison to other disability groups.[67] Regardless of whether an individual has directly experienced discrimination in the work place, the fear and anticipation of such an event is common and negatively influences PHAs’ decisions regarding employment.[33] The labour force participation literature also documented alienation by coworkers and a general insensitivity towards all people with disabilities as additional employment obstacles for many PHAs.[48, 68] Likewise, evidence suggests that homophobia and other negative stereotypes regarding some sub-groups of PHAs are prevalent.[6, 66] Unfortunately, very few related facilitators are discussed in the literature beyond a general need for initiatives to address the phenomenon. 
Disclosure. Some studies have identified PHAs' fears regarding work place disclosure as an additional barrier to successful employment.[69, 70] Many of these have described increased stress experienced by many PHAs related to both voluntary and involuntary disclosure of their HIV status in the work place.[33, 35, 48, 62] Consequently, many PHAs conceal their status in order to protect against negative attitudes and hurtful responses.[70, 71] The literature identifies some important facilitators that can assist PHAs in managing this tension. These include support from human resource professionals and the development of a comprehensive disclosure plan.[71, 72]

Work Environment and Workplace Accommodation. Factors contributing to the workplace environment and the need for accommodation have been identified within the employment literature as important considerations for PHAs. A non-supportive work environment is frequently cited as a barrier for PHAs who are considering return to work or maintaining ongoing employment.[48, 62] Working conditions incompatible with the management of HIV have been reported to cause increased stress negatively affecting the health of PHAs.[2] A lack of HIV knowledge among co-workers and managers, poor flexibility in the work place, and lack of appropriate accommodation are described in several studies as contributing to these conditions and leading to decreased quality of employment options for PHAs.[23, 26, 61]

A range of work place accommodations are described in some studies as supportive of improved work environments for PHAs. Flexible work schedules, the possibility of part time work, increased time off for medical appointments and reassignment to less physically demanding jobs are all promoted as accommodations that facilitate improved employment options for PHAs. [1, 39, 73] 
Job Skills, Work Experience and Education. Within a competitive labour market structure, an individual's skills, experience and education can serve as critical factors for successful labour force participation. Several studies within the labour force participation literature address these factors as potential barriers that affect PHAs and their employment options. PHAs and individuals with disabilities are especially vulnerable to structural barriers that shape the employment experience; these can include difficult economic conditions and an uncertain job market.[23, 64] Within this context are a range of personal characteristics that can serve as barriers to employment. Low levels of job skills, education and training are described as inhibiting success in the workplace.[32, 55, 64] A lack of professional experience and previous periods of unemployment can also serve as obstacles to obtaining employment for PHAs.[32, 35, 64] Additional psychological factors related to the job search process, such as fear of failure and poor self confidence can prevent PHAs from meeting their work-related goals.[39, 42] Alternatively, higher levels of occupational position, increased education and shorter periods of prior unemployment are associated with improved employment outcomes and are viewed in the labour force participation literature as facilitators.[53]

Job Characteristics. Many PHAs consider changing careers and may opt to pursue alternative types of employment in order to find work that is psychologically and emotionally rewarding and that provides fulfillment beyond simple financial compensation.[62, 74] Also reported as important by PHAs who have participated in several studies are positions that are self directed, mentally challenging, meaningful and that offer opportunities for career advancement.[34, 39] Consequently many PHAs consider vocational alternatives that facilitate a change in the type of engagement in the work force. This often includes paid positions or activities outside the formal 
labour force including care giving roles, community involvement and volunteer positions, sometimes within a local AIDS service organization.[16, 61]

Work place HIV Education and Support Programs. The labour force participation literature has identified a range of measures that if implemented by employers could serve to facilitate improved employment outcomes for PHAs. Comprehensive AIDS awareness training for all employers and employees is commonly recommended as an important facilitator.[68, 75, 76] Additional supportive actions include the establishment of an AIDS information office, regular communication on HIV/AIDS and coordination among all departments.[77]

Work place Policies. A work place policy structure supportive of HIV issues and support programs is suggested by several authors as an additional facilitator of labour force participation for PHAs. Policies that encourage a consistent and structured approach to the issue may alleviate PHAs’ fears regarding stigma and disclosure.[75] Likewise, several studies recommend workplace policies and position statements on HIV/AIDS that address confidentiality of employee records, benefits structures, and reasonable accommodation.[48, 68, 75, 77, 78]

\section{Community Domain}

The final conceptual domain structuring the barriers and facilitators category is the community level. This domain has received increasing attention recently within the labour force participation literature.

Vocational Services. Access to effective vocational services is described in the literature as an important employment facilitator for PHAs. A broad range of supports are documented as contributing to successful employment, including community-based return to work programs, offsite vocational counseling and on-site job support.[35, 37, 79] Successful return to work programs often include services that are strengths-based, individualized, job specific and that 
allow for a facilitated adjustment to the workforce.[35, 58, 80] Furthermore, effective vocational interventions for PHAs are described as those that provide ongoing assessment of client needs and support for related issues such as mental health problems or addictions.[58]

Despite evidence related to the efficacy of vocational services, a range of barriers associated with their delivery have also been identified in the literature. Very few AIDS service organizations receive dedicated resources to provide employment related supports, requiring many PHAs to receive vocational services from conventional agencies.[22] Unfortunately, some authors have identified discriminatory attitudes and negative stereotypes about PHAs among mainstream vocational service providers, including the belief that they are unemployable.[22, 62] Additionally, some studies question the effectiveness of vocational service providers, suggesting that they are not adequately trained to assist PHAs to assess the potential benefits and risks of employment.[22, 70] Other barriers related to vocational service provision include a general lack of access for PHAs and few avenues for the sharing of information and networking among service providers.[22]

Access to Community Resources. Poor access to community resources is an employment barrier that further exacerbates the conditions of social inequity within which many PHAs live. Poor access to transportation and childcare has repeatedly been acknowledged in the labour force participation literature as a significant barrier for many PHAs who wish to return to work.[23, 58, 64] Consequently it is those PHAs who are poor or disenfranchised who have fewer alternate resources and to whom employment may be of greatest relevance.[35]

Social Inequities. Poverty and low socioeconomic status have been cited as obstacles to employment for many PHAs, as have homelessness and unstable living situations.[35, 54, 64] Contributing to these barriers are social factors that inhibit PHAs from participating fully in the 
labour force. In some jurisdictions the high costs of medication can create inequitable access to antiretroviral medications, threatening the health of uninsured PHAs and preventing their full employment.[81] In an era where effective treatment can be the gateway to successful employment, the literature suggests that the inequitable distribution of antiretroviral medications has led to a socially differentiated impact of HIV infection.[32]

Access to Information. The many barriers that structure the employment experiences of PHAs are aggravated by poor access to relevant information. Escovitz and Donegan (2005) identified the lack of information regarding employee rights and job accommodations as a significant barrier to employment for PHAs.[35] Others suggested a range of options that could facilitate labour force participation. Specific and accessible information regarding workplace disclosure and job discrimination could assist PHAs to make better informed vocational decisions.[39] Preemployment awareness of and access to information regarding an employer's policies and group insurance coverage would benefit PHAs who are considering a return to work or contemplating a job change as would information regarding the legal obligations of potential employers.[1, 82] The provision of these types of information would support PHAs who are anxious about considering employment and who are fearful of losing their existing disability supports and health care insurance.

Social Supports. An array of factors, both formal and informal, may reduce the employment barriers related to lack of resources. The labour force participation literature describes numerous social supports that can assist PHAs to successfully return to work and maintain their employment over a sustained period of time. Key among these are personal supports. A number of studies report that a stable partnership or family support can be an important employment facilitator and that many PHAs use these personal supports prior to seeking professional 
resources when dealing with an employment related issue.[44, 83, 84] Also described in the literature are a range of community facilitated peer supports. Peer programs, buddy systems, and support groups are cited as effective social supports that can facilitate improved employment situations for PHAs.[48, 58] Additionally, professionally delivered services such as benefits counseling, case management, education programs and addictions counseling are commonly reported as formal social supports beneficial to PHAs considering labour force participation.[39, 85]

\section{Factors Influencing Vulnerable Populations}

The complex and dynamic nature of HIV infection influences the employment experiences of PHAs. Consequently, in addition to the aforementioned barriers and facilitators commonly experienced by PHAs, specific issues exist for different communities based on the interaction between personal, contextual and health-related factors.[86] Unemployment for PHAs is frequently related to socioeconomic status and other personal characteristics.[35, 87, 88] The labour force participation literature identifies specialized needs and barriers related to several vulnerable populations, notably gay men, racial and ethnic minorities, women, injection drug users, PHAs living in rural areas and youth. As much of the existing labour force participation literature has drawn from the experiences of gay male PHAs, several recent studies have begun to document factors pertaining to other vulnerable populations.

Several studies document specific employment barriers that affect PHAs from ethnic minority groups. These include decreased access to economic resources and education, higher rates of drug use and mental health issues.[88, 89] Some studies also reported differential factors related to employment outcomes including decreased levels of physical functioning, and lower quality of life.[89, 90] Finally, the labour force participation literature suggested that economic factors 
disproportionately affected PHAs from ethnic minority groups, the consequences of which are higher levels of unemployment, poorer access to treatment and a high degree of uncertainty regarding the course of illness.[87, 91]

Marginalization due to gender and poverty create obstacles to employment for many women living with HIV.[86] Several health related and personal barriers are identified in the handful of studies that address labour force participation for female PHAs. Included among these are gynecological problems, fatigue, loss of concentration, depression, and general symptoms of HIV.[86, 92] However, contextual issues are more commonly reported as stressors, suggesting that women experience a unique set of conditions that structure the employment experience. Pressures related to the gendered nature of economic marginalization and unsupportive social networks may result in absenteeism, lowered quality of work and fear of job loss for many employed women.[92] Additionally, the maternal role is frequently emphasized in the literature as a barrier to employment as are other issues related to family care giving, marital relations and domestic violence.[35, 93]

Substance use is frequently identified in the literature as a general barrier to employment.[34] Also recognized is a set of distinct factors that both limit and prevent successful labour force participation for injection drug users. Lack of stable housing, limited employable skills, a history of incarceration, and low levels of education may make it difficult for injection drug users to find stable employment.[35] High rates of Hepatitis C co-infection found among some injection drug users further threatens successful employment outcomes.[32, 94]

Although limited in scope, some specific factors affecting PHAs who live in rural areas and youth are discussed in the literature on labour force participation. Employment obstacles for PHAs living in non urban settings include lack of access to medical professionals, lack of 
transportation and increased HIV stigma.[95] Evidence regarding the needs and perspectives of youth living with HIV are now emerging and indicate that generally those of older age are at a disadvantage in employment situations and youth who are conscious of their occupational opportunities are less likely to experience emotional distress and more likely to use positive coping strategies to address any barriers.[88, 96, 97]

\section{Strategies and Support}

A fourth major component in the conceptual framework on HIV and labour force participation is strategies and supports that may assist PHAs in returning to work or sustaining employment With employment specific support services, PHAs who experience barriers to employment can be helped to work if they so choose.[85, 98, 99] Moreover, numerous studies documented the efficacy of various vocational supports for PHAs. In several experimental or quasi-experimental studies, PHAs participating in vocational interventions were found to be more likely to return to work than those in control or comparison groups.[85] Generally, employment services have been found to assist PHAs in becoming more psychologically prepared for employment by increasing their confidence, motivation and self respect and by facilitating their adjustment to the workplace.[37, 80, 85]Additionally, the literature supports a range of factors that characterize successful interventions. Some authors advocate for HIV specific employment programs instead of mainstream services provided for other disability groups.[44] Other studies promote service coordination, collaboration between service providers and the importance of advocacy for legislation and public policy reform.[35, 40, 64] Regardless of their focus, studies suggest that services are best structured around the needs of PHAs.[46] These needs are frequently differentiated according to employment status - unemployed individuals require return to work supports while those employed require assistance to sustain it.[44] 


\section{Supporting Return to Work}

Numerous strategies for supporting PHAs who wish to return to work are identified in the labour force participation literature. Strengths based, HIV-specific, holistic, and individualized approaches are all described as well suited to meeting the specialized needs of PHAs.[49, 100] A peer support model that provides opportunities to connect with other PHAs from a similar background is recognized as effective by some authors, as are services provided by respectful and culturally sensitive vocational professionals.[80, 101] Skill development is consistently identified as an important feature of return to work programs and may include an emphasis on practical skills such as computer training, resume writing and interviewing.[39, 100] Advocacy when necessary as well as dialogue that counters cultural messages regarding illness and stigma are additional practices that can assist PHAs to overcome the complex barriers associated with returning to work [35, 80]

\section{Sustaining Employment}

Ongoing supports for PHAs who are successfully employed are crucial and frequently differ from those who are in the pre-employment phase. PHAs in employment situations may require increased support when navigating a range of obstacles associated with the workplace. Support for disclosure, assistance in communicating with employers, and help negotiating accommodations are specialized on site job supports frequently discussed in the literature.[35, 72] Also valuable to PHAs is offsite vocational counseling to address job related problem solving and support the development of appropriate coping skills.[35] Occupational therapy may assist PHAs who require workplace modifications and can provide support for dealing with future transitions.[102] Finally, the presence of an informed mentor or support person in the work place is reported to be effective in supporting PHAs to sustain ongoing employment.[69] 


\section{Outcomes of Labour Force Participation}

The fifth and final major component of the preliminary framework deals with the outcomes of labour force participation. Many PHAs approach employment with a degree of ambiguity, and the labour force participation literature identifies many benefits and some risks associated with employment that may accrue to both PHAs and employers.

\section{Benefits and Risks for Individuals}

For PHAs, several studies report employment as being strongly associated with higher health related quality of life; concluding that employed PHAs have higher physical functioning, fewer physical limitations, less pain, slower disease progression and better perceived general health.[4, 103-105] The social benefits related to employment for PHAs are well documented. Labour force participation can contribute to a sense of well being and belonging, a stronger sense of personal identity and improved self esteem.[35, 80] Alternatively, work stress is a potential risk associated with labour force participation and may lead to negative health effects for PHAs.[33, 70]

\section{Benefits and Risks for Employers}

There is very little literature on the benefits and risks related to businesses and organizations who employ PHAs. However a few studies and reports suggest that advantages related to increased labour force participation may also accrue to employers through substantially lower insurance costs for the company, increased productivity and decreased costs related to litigation.[77, 106] Raising equity and morale throughout the organization, maintaining an organization's reputation as a responsible corporate citizen and attracting and retaining qualified employees are also cited as possible benefits for employers.[106] A potential risk includes the costs associated with accommodation.[77] 


\section{Strength and Limitations}

To our knowledge, this review was the first to use scoping study methodology to develop a conceptual framework of labour force participation for PHAs. Accordingly, several strengths and challenges emerged with this approach. A key strength of this scoping study was the level of engagement of community partners including PHAs, employers, service providers, policy makers and community members. Participatory approaches and ongoing involvement of community members contributed to the relevance of the framework and ensured that key themes were not neglected. Members of the community advisory committee were knowledgeable about the HIV and labour force field, heightening the overall rigor of the scoping study, including the validity of our framework and its usefulness to practice in the field.

One limitation associated with this scoping study is the nature and quality of the existing literature base. Because no methodological quality review occurs with scoping studies, members of the research team were uncertain how to weigh the grey literature in relation to the peerreviewed literature. Furthermore, feasibility constraints limited the resources available for the review. Two team members independently reviewed the abstracts for inclusion, and a team of 3 individuals extracted data from the included studies. To offset this limitation, the team met throughout to ensure clarity and consensus surrounding the nature and extent of data extracted from the studies.

Due to the variations in accessibility of antiretroviral therapy, we focused on the labour force participation literature from industrialized countries, including Canada and United States. However, differences in social supports, access to health services, labour force and income support policies across jurisdictions may still exist requiring one to consider the applicability of findings in a given context. 


\section{CONCLUSION}

Given the success of HIV/AIDS treatments, labour force participation will continue to be a key concern for many PHAs. As a key social driver affecting health and quality of life, it is also a key concern for service providers and policy makers. This scoping study builds on earlier reviews and provides a synthesis of the current literature on labour force participation for PHAs in domains beyond individual intervention approaches. A comprehensive and integrated body of literature addressing labour force participation is a critical tool for developing relevant employment programs and policy. To achieve this, research on key factors influencing employment for PHAs is needed as are studies that document the associated impact of public policy and community programs on labour force participation and PHAs.

The current literature addressing labour force participation for PHAs has effectively begun to explore the employment-related challenges facing many PHAs. Five commonly identified components in the literature include the meaning of work; key factors (barriers and facilitators) influencing labour force participation, factors affecting vulnerable populations, strategies and supports for returning to or sustaining work, and the outcomes (benefits and risks) of labour force participation for individuals and employers. While the labour force participation literature provides early evidence related to barriers, more research is required into the types and natures of interventions that could be effective in supporting PHAs who choose employment. Additionally, several authors acknowledged limitations associated with the current status of the employment literature on labour force participation for PHAs. This includes a critique of the labour force participation literature as disproportionately reflecting the service needs of a small, homogonous group of male clients. Indeed, only a small number of studies focus on issues 
related to the other diverse communities affected by HIV/AIDS. Both Werth (2008) and Conyers (2008) identified a need for more HIV/AIDS and employment research that effectively considers issues such as race, gender, addictions, poverty, and mental health.[17, 26] The labour force participation literature is steadily moving towards addressing these issues while simultaneously shifting from identification and analysis of individual, personal and psychological constructs to a broader lens that also investigates the impact of contextual and structural factors on HIV/AIDS and employment. Additionally, Ferrier and Lavis (2003) suggest that our current understanding of return to work focuses on easily measured factors that only explain short term disability.[1] These limitations highlight a growing need for research that reflects the longitudinal episodic nature of HIV/AIDS and explores its impact on employment processes. Furthermore, several authors stress that labour force participation is one choice among many vocational options open to PHAs and that individuals should remain free to decide whether or not to engage in the formal labour force.[1, 26] Other forms of meaningful activity may also support wellness and increased social participation. Common among these are alternatives such as physical and recreational activities or volunteer positions. Nevertheless, employment remains a key focus for many PHAs and may serve as a critical step towards increased self determination and independence. A continued focus on employment outcomes and strategies that address employment related issues would be beneficial to AIDS service organizations and others involved in supporting PHAs.

Very little research exists that comprehensively examines the outcomes associated with labour force participation for PHAs. There is a need for an increased focus on evaluating existing vocational programs and their potential impact on employment processes for PHAs. An additional gap is research that addresses issues within the employment and public policy domain 
and research that examines issues related to insurers. Interdisciplinary research from a variety of perspectives that address these factors would provide additional evidence to support the planning and provision of effective vocational services for PHA who choose employment. 
Acknowledgements: The authors would like to thank the Community Advisory Committee members. We also would like to acknowledge contributions to this research by Elizabeth Uleryk (Hospital for Sick Children, Library) for her role in developing the search strategy, and Mary Goitam, Ramona Snider, Marla Beauchamp, Adrian Guta and Olivia Kitt for assistance with article retrieval, data extraction, and clerical assistance. Funding for this research was provided by the Canadian Institutes of Health Research (CIHR).

C. Worthington was a CIHR New Investigator at the time of the study; K. O’Brien is supported by a fellowship from the CIHR and a Michael DeGroote Postdoctoral Fellowship (McMaster University). 


\section{REFERENCES}

1) Ferrier S, Lavis J. With health comes work? people living with HIV/AIDS consider returning to work. AIDS Care. Jun 2003;15(3):423-435.

2) Dray-Spira R, Lert F. Living and working with HIV in France in 2003: results from the ANRS-EN12-VESPA Study. AIDS. 2007;21(1):S29-S36.

3) Braveman B, Levin M, Kielhofner G, Finlayson M. HIV/AIDS and return to work: a literature review one-decade post-introduction of combination therapy (HAART). WORK. 2006;27(3):295303.

4) Worthington C, Krentz HB. Socio-economic factors and health-related quality of life in adults living with HIV. Int J STD AIDS. 2005;16(9):608-614.

5) Burgoyne RW, Saunders DS. Perceived support in newly registered HIV/AIDS clinic outpatients. AIDS Care. 2000;12(5):643-650.

6) Dray-Spira R, Gueguen A, Lert F. Disease severity, self-reported experience of workplace discrimination and employment loss during the course of chronic HIV disease: differences according to gender and education. Occup Environ Med. Feb 2008;65(2):112-119.

7) Cunningham W, Anderson R, Katz M. The impact of competing subsistence needs and barriers on access to medical care for persons with human immunodeficiency virus receiving care in the United States. Med Care. 1999;37:1270-1281.

8) Ezzy D, de Visser R, Bartos M. Poverty, disease progression and employment among people living with HIV/AIDS in Australia. AIDS Care. Aug 1999;11(4):405-414.

9) Health Canada, Wellesley Central Hospital. Module 7: rehabilitation services: a comprehensive guide for the care of persons with HIV disease. Toronto: Health Canada Wellesley Central Hospital;1998. 
10) Hammarstrom A, Janlert U. Early unemployment can contribute to adult health problems: results from a longitudinal study of school leavers. Journal of Epidemiol Community Health. 1987;56(624-630).

11) Auerbach JD, Parkhurst JO, Caceres CF, Keller KE. Addressing social drivers of HIV/AIDS: Some conceptual, methodological, and evidentiary considerations. aids2031 Working Paper No 24. 2009. Accessed http://www.aids2031.org/working-groups/social-drivers.

12) Price R. Links in the chain of adversity following job loss: how financial strain and loss of personal control lead to depression, impaired functioning, and poor health. J Occup Health Psychol. 2002;7:302-312.

13) Morris J, Cook D, Shaper A. Loss of employment and mortality. Br Med J. 1994;308:11351139.

14) Dray-Spira R, Gueguen A, Persoz A, et al. Temporary employment, absence of stable partnership, and risk of hospitalization or death during the course of HIV infection. $J$ Acquir Immune Defic Syndr. Oct 2005;40(2):190-197.

15) Blalock AC, McDaniel JS, Farber EW. Effect of employment on quality of life and psychological functioning in patients with HIV/AIDS. Psychosomatics. 2002;43(5):400-404.

16) Blustein DL, Catraio C, Coutinho MT, Murphy KA. Lessons in survival: forging an experience-near understanding of the interface of work and health. Counseling Psychologist. Jan 2008;36(1):90-97.

17) Conyers L. HIV/AIDS and employment research: A need for an integrative approach. Counseling Psychologist. Jan 2008;36(1):108-117.

18) Bhaskaran $K$, Hamouda $O$, Sannes $M$, et al. Changes in the risk of death after seroconversion compared with mortality in the general population. JAMA. 2008;300:51-59. 
19) Hoy-Ellis CP, Fredrikson-Goldsen K. Is AIDS chronic or terminal? the perceptions of persons living with AIDS and their informal support partners. AIDS Care. 2007;19(835-843). 20) Rabkin JG, McElhiney M, Ferrando SJ, Van Gorp W, Lin SH. Predictors of employment of men with HIV/AIDS: a longitudinal study. Psychosom Med. 2004;66(1):72-78.

21) Canadian AIDS Society. Force for change labour force participation for people living with HIV/AIDS: Canadian AIDS Society;1998.

22) Ciasullo E, Escovitz K. Positive futures: the need for paradigm shift in HIV/AIDS services. $J$ Vocat Behav. 2005;22(2):125-128.

23) Maguire CP, McNally CJ, Britton PJ, Werth JL, Jr., Borges NJ. Challenges of work: voices of persons with HIV disease. Counseling Psychologist. Jan 2008;36(1):42-89.

24) Goldblum P, Kohlenberg B. Vocational counseling for people with HIV: the client-focused considering work model. Journal of Vocational Rehabilitation. 2005;22(2):115-124.

25) Hergenrather KC, Rhodes SD, Clark G. Employment-seeking behavior of persons with HIV/AIDS: a theory-based approach. $J$ Rehabil. Oct-Dec 2004;70(4):22-32.

26) Werth JL, Jr., Borges NJ, McNally CJ, Maguire CP, Britton PJ. The intersections of work, health, diversity, and social justice: Helping people living with HIV disease. Counseling Psychologist. Jan 2008;36(1):16-41.

27) Mays N, Roberts E, Popay J. Synthesizing research evidence In: Fulop P, Allen A, Clarke A, Black A, eds. Studying the organisation and delivery of health services: research methods. London: Routledge; 2001.

28) Arksey H, O'Malley L. Scoping studies: towards a methodological framework. International Journal of Social Research Methodology. 2005;8(1):19-32. 
29) Statistics Canada. Guide to the labour force survey. In: Labour Statistics Division LFSP, ed. Otttawa: Labour Statistics Division, Labour Force Survey Program; 2010.

30) Fish G, Rudman DL. The potential role of occupational therapy in acute care with clients with HIV/AIDS. Occupational Therapy International. 1998;5(1):1-16.

31) Ezzy D, de Visser R, Grubb I, McConachy D. Employment, accommodation, finances and combination therapy: the social consequences of living with HIV/AIDS in Australia. AIDS Care. Jun 1998;10 Suppl 2:S189-199.

32) Dray-Spira R, Gueguen A, Ravaud J-F, Lert F. Socioeconomic differences in the impact of HIV infection on workforce participation in France in the era of highly active antiretroviral therapy. Am J Public Health. Mar 2007;97(3):552-558.

33) Brooks RA, Martin DJ, Ortiz DJ, Veniegas RC. Perceived barriers to employment among persons living with HIV/AIDS. AIDS Care. 2004;16(6):756-766.

34) Dickson-Gomez JB, Knowlton A, Latkin C. Values and identity: the meaning of work for injection drug users involved in volunteer HIV prevention outreach. Subst Use Misuse. Jun 2004;39(8):1259-1286.

35) Escovitz K, Donegan K. Providing effective employment supports for persons living with HIV: the KEEP project. Journal of Vocational Rehabilitation. 2005;22(2):105-114.

36) The Canadian Working Group on HIV and Rehabilitation. Policy issues on rehabilitation in the context of HIV disease a background and position paper. Toronto2000.

37) Kielhofner G, Braveman B, Finlayson M, Paul-Ward A, Goldbaum L, Goldstein K. Outcomes of a vocational program for persons with AIDS. Am J Occup Ther. Jan-Feb 2004;58(1):64-72. 
38) Conyers L. Expanding understanding of HIV/AIDS and employment: perspectives of focus groups. Rehabilitation Counseling Bulletin. 2004;48(1):5-18, 59-60.

39) Brooks RA, Klosinski LE. Assisting persons living with HIV/AIDS to return to work: programmatic steps for AIDS service organizations. Aids Educ Prev. Jun 1999;11(3):212-223. 40) McReynolds CJ. The meaning of work in the lives of people living with HIV disease and AIDS. Rehabilitation Counseling Bulletin. Win 2001;44(2):104-115.

41) Hergenrather KC, Rhodes SD, Clark G. The employment perspectives study: identifying factors influencing the job-seeking behavior of persons living with HIV/AIDS. Aids Educ Prev. Apr 2005;17(2):131-142.

42) Nixon S, Renwick R. Experiences of contemplating returing to work for people living with HIV/AIDS. Qual Health Res. Nov 2003;13(9):1272-1290.

43) Braveman B, Helfrich CA. Occupational identity: exploring the narratives of three men living with AIDS. J Occup Sci. Aug 2001;8(2):25-31.

44) Timmons JC, Fesko SL. The impact, meaning, and challenges of work: perspectives of individuals with HIV/AIDS. Health Soc Work. May 2004;29(2):137-144.

45) Dray-Spira R, Lert F, Marimoutou C, Bouhnik AD, Obadia Y. Socio-economic conditions, health status and employment among persons living with HIV/AIDS in France in 2001. AIDS Care Psychological and Socio Medical Aspects of AIDS/HIV. 2003;15(6):739-748.

46) Vetter CJ, Donnelly JP. Living long-term with HIV/AIDS: exploring impact in psychosocial and vocational domains. WORK: A Journal of Prevention, Assessment \& Rehabilitation. 2006;27(3):277-286.

47) Anandan N, Braveman B, Kielhofner G, Forsyth K. Impairments and perceived competence in persons living with HIV/AIDS. Work. 2006;27(3):255-266. 
48) Hyduk C, Kustowski K. Helping people coping with HIV and AIDS manage employment. In: Moxley DP, Finch JR, eds. Sourcebook of rehabilitation and mental health practice. New York, NY: Kluwer Academic/Plenum Publishers; 2003:417-431.

49) McReynolds C. Human immunodeficiency virus (HIV) disease: shifting focus toward the chronic, long-term illness paradigm for rehabilitation practitioners. Journal of Vocational Rehabilitation. 1998;10(3):231-240.

50) Van Gorp WG, Rabkin JG, Ferrando SJ, et al. Neuropsychiatric predictors of return to work in HIV/AIDS. J Int Neuropsychol Soc. 2007;13(1):80-89.

51) Bogart LM, Catz SL, Kelly JA, et al. Psychosocial issues in the era of new AIDS treatments from the perspective of persons living with HIV. Journal of Health Psychology. 2000;5(4):500516.

52) Goldman DP, Bao Y. Effective HIV treatment and the employment of HIV positive adults. Health Serv Res. 2004;39(6 I):1691-1712.

53) Dray-Spira R, Persoz A, Boufassa F, et al. Employment loss following HIV infection in the era of highly active antiretroviral therapies. European Journal of Public Health. 2006;16(1):8995.

54) Grierson J, Pitts M, Whyte M, et al. Living with HIV in New Zealand: balancing health and quality of life. $N$ Z Med J. 2004;117(1200).

55) Johnson ME, Reynolds GL, Fisher DG. Employment status and psychological symptomatology among drug users not currently in treatment. Eval Program Plann. May 2001;24(2):215-220.

56) Braveman B, Helfrich C, Kielhofner G, Albrecht G. The narratives of 12 men with AIDS: exploring return to work. Journal of Occupational Rehabilitation. 2003;13(3):143-157. 
57) Goldstein K, Kielhofner G, Paul-Ward A. Occupational narratives and the therapeutic process. Australian Occupational Therapy Journal. Sep 2004;51(3):119-124.

58) Martin DJ, Steckart MJ, Arns PG. Returning to work with HIV/AIDS: a qualitative study. WORK: A Journal of Prevention, Assessment \& Rehabilitation. 2006;27(3):209-219.

59) Canadian HIV/AIDS Legal Network. Support for Survival: barriers to income security for people living with HIV/AIDS and directions for reform: Canadian HIV/AIDS Legal Network;2005.

60) McGinn F, Gahagan J, Gibson E. Back to work: vocational issues and strategies for Canadians living with HIV/AIDS. Work. 2005;25(2):163-171.

61) Hunt B, Jaques J, Niles SG, Wierzalis E. Career concerns for people living with HIV/AIDS. Journal of Counseling and Development. 2003;81(1):55-60.

62) Caulfield M, Carey CS, Mason CY. Project Employ: rehabilitation services facilitating employment of individuals with HIV/AIDS. Am Rehabil. 1994;20(3):12-16.

63) The Canadian Working Group on HIV and Rehabilitation. Unpredictable Episodes of Illness in the Experiences of Persons Living with HIV/AIDS: A Qualitative Study: The Canadian Working Group on HIV and Rehabilitation;2003.

64) Paul-Ward A, Kielhofner G, Braveman B, Levin M. Resident and staff perceptions of barriers to independence and employment in supportive living settings for persons with AIDS. Am J Occup Ther. 2005;59(5):540-545.

65) The Canadian Working Group on HIV and Rehabilitation. Looking Beyond the Silo:

Disability issues in HIV and Other Lifelong Episodic Conditions. Toronto: Canadian Working Group on HIV and Rehabilitation;2002.

66) Adkins L. Risk, sexuality and economy. Br J Sociol. Mar 2002;53(1):19-40. 
67) Conyers L, Rumrill Jr PD. A comparison of equal employment opportunity commission case resolution patterns of people with HIV/AIDS and other disabilities. Journal of Vocational Rehabilitation. 2005;22(3):171-178.

68) Tammi SS. Implementing an AIDS policy. retaining and promoting productivity in the workplace. AAOHN J. Jun 1991;39(6):276-280.

69) Breuer NL. Teaching the HIV-positive client how to manage the workplace. Journal of Vocational Rehabilitation. 2005;22(3):163-169.

70) Glenn MK, Ford JA, Moore D, Hollar D. Employment issues as related by individuals living with HIV or AIDS. J Rehabil. 2003;69(1):30-36.

71) Fesko SL. Disclosure of HIV status in the workplace: considerations and strategies. Health Soc Work. Nov 2001;26(4):235-244.

72) Allen S, Carlson G. To conceal or disclose a disabling condition? a dilemma of employment transition. Journal of Vocational Rehabilitation. 2003;19(1):19-30.

73) Walch SE, Lezama MA, Giddie LT. Research tools: managing HIV in the workplace: a primer for managers and supervisors. Psychologist Manager Journal. 2005;8(1):55-73.

74) Jalbert Y. Triple-drug therapy and return to work: results of a Quebec survey. Canadian HIV-AIDS Policy \& Law Newsletter. Winter 1997;3-4(4-1):13-16.

75) Gadd K, Goss D. HIV/AIDS education in the workplace: "it's not my responsibility ....". In: Catalan J, Sherr L, Hedge B, eds. The Impact of AIDS: Psychological and Social Aspects of HIV Infection. Amsterdam: Harwood Academic Publishers; 1997:51-58.

76) O'Brien GV, Koerkenmeier M. Persons with HIV/AIDS in the workplace: implications for employee assistance professionals. Employee Assistance Quarterly. 2001;16(3):9-23. 
77) Booth IM. Corporations that confront the scourge of AIDS. Business and Society Review. 1993;85:21.

78) Bell-Rowbotham B. AIDS in the workplace. Benefits Canada. 1997;5:69-74.

79) Braveman BH. Development of a community-based return to work program for people with AIDS. Occupational Therapy in Health Care. 2001;13(3/4):113-131.

80) Conyers L. The impact of vocational services and employment on people with HIV/AIDS. Work. 2004;23(3):205-214.

81) McFarland W, Chen S, Hsu L, Schwarcz S, Katz M. Low socioeconomic status is associated with a higher rate of death in the era of highly active antiretroviral therapy, San Francisco. $J$ Acquir Immune Defic Syndr. 2003;33(1):96-103.

82) Pranschke SC, Wright BM. HIV and AIDS - employers grapple with difficult issues. Benefits Q. 1995;11(3):41-48.

83) Sendi P, Schellenberg F, Ungsedhapand C, et al. Productivity costs and determinants of productivity in HIV-infected patients. Clin Ther. 2004;26(5):791-800.

84) Jia H, Uphold CR, Wu S, Reid K, Findley K, Duncan PW. Health-related quality of life among men with HIV infection: effects of social support, coping, and depression. Aids Patient Care STDS. 2004;18(10):594-603.

85) Martin DJ, Arns PB, Batterham PJ, Afifi AA, Steckart MJ. Workforce reentry for people with HIV/AIDS: intervention effects and predictors of success. WORK: A Journal of Prevention, Assessment \& Rehabilitation. 2006;27(3):221-233.

86) Solomon P, Wilkins S. Participation among women living with HIV: a rehabilitation perspective. AIDS Care Psychological and Socio Medical Aspects of AIDS/HIV. 2008;20(3):292296. 
87) Hoffman MA. HIV disease and work: effect on the individual, workplace, and interpersonal contexts. J Vocat Behav. Oct 1997;51(2):163-201.

88) Joyce GF, Goldman DP, Liebowitz AA, Alpert A, Bao Y. A socioeconomic profile of older adults with HIV. J Health Care Poor Underserved. Feb 2005;16(1):19-28.

89) Burns SM, Young LRL, Maniss S. Predictors of employment and disability among people living with HIV/AIDS. Rehabilitation Psychology. May 2006;51(2):127-134.

90) Vidrine DJ, Amick BC, 3rd, Gritz ER, Arduino RC. Functional status and overall quality of life in a multiethnic HIV-positive population. Aids Patient Care STDS. Apr 2003;17(4):187-197. 91) Speer DC, Kennedy M, Watson M, Joan Meah JN, Watson B. Ethnic, demographic, and social differences among middle and older adults with HIV/AIDS. Aids Patient Care STDS. 1999;13(10):615-624.

92) Semple SJ, Patterson TL, Temoshok LR, et al. Identification of psychobiological stressors among HIV-positive women. Women Health. 1993;20(4):15-36.

93) Onwumere J, Holttum S, Hirst F. Determinants of quality of life in black African women with HIV living in London. Psychology, Health and Medicine. 2002;7(1):61-74.

94) Dray-Spira R, Lert F. Social health inequalities during the course of chronic HIV disease in the era of highly active antiretroviral therapy. AIDS. 2003;17(3):283-290.

95) Heckman TG, Somlai AM, Peters J, et al. Barriers to care among persons living with HIV/AIDS in urban and rural areas. AIDS Care Psychological and Socio Medical Aspects of AIDS/HIV. 1998;10(3):365-375.

96) Burns SM, Young LRL, Maniss S. Factors associated with employment among latinos living with HIV/AIDS. J Rehabil. 2007;73(1):29-37. 
97) Lightfoot M, Healy C. Career development, coping, and emotional distress in youth living with HIV. Journal of Counseling Psychology. 2001;48(4):484-489.

98) Paul-Ward A, Braveman B, Kielhofner G, Levin M. Developing employment services for individuals with HIV/AIDS: participatory action strategies at work. Journal of Vocational Rehabilitation. 2005;22(2):85-93.

99) Lee RKY, Chan CCH. Factors affecting vocational outcomes of people with chronic illness participating in a supported competitive open employment program in Hong Kong. WORK: A Journal of Prevention, Assessment \& Rehabilitation. 2005;25(4):359-368.

100) Bowyer $P$, Kielhofner $G$, Braveman $B$. Interdisciplinary staff perceptions of an occupational therapy return to work program for people living with AIDS. WORK: A Journal of Prevention, Assessment \& Rehabilitation. 2006;27(3):287-294.

101) Berry JD, Hunt B. HIV/AIDS 101: a primer for vocational rehabilitation counselors. Journal of Vocational Rehabilitation. 2005;22(2):75-83.

102) Salz F. HIV/AIDS and work: the implications for occupational therapy. WORK: A Journal of Prevention, Assessment \& Rehabilitation. 2001;16(3):269-272.

103) Huba GJ, Melchior LA, Cherin DA, et al. Service needs and factors related to quality of life at time of service enrollment among persons living with HIV. Home Health Care Serv Q. 2000;18(3):43-63.

104) Cowdery JE, Pesa JA. Assessing quality of life in women living with HIV infection. AIDS Care Psychological and Socio Medical Aspects of AIDS/HIV. 2002;14(2):235-245.

105) Sowell RL, Seals BF, Moneyham L, Demi A, Cohen L, Brake S. Quality of life in HIVinfected women in the south-eastern United States. AIDS Care Psychological and Socio Medical Aspects of AIDS/HIV. 1997;9(5):501-512. 
106) The Interagency Coalition on AIDS and Development. HIV/AIDS as an episodic disability in the workplace an environmental scan: Interagency Coalition on AIDS and Development; September 20052005. 
